\title{
Comparison of Flow and Solubility Properties of Mineral Trioxide Aggregate Cement with Two Additive Plasticizing Agents: An In Vitro Study
}

\author{
Ligia Gusmão Santos, ${ }^{1}$ Aline Evangelista Souza Gabriel, ${ }^{2}$ Antonio Miranda Cruz Filho, ${ }^{3}$ Ricardo Novak Savioli ${ }^{4 *}$ \\ ${ }^{1}$ Student of School of Dentistry of Ribeirão Preto USP, São Paulo, Brazil \\ ${ }^{2,3,4}$ Professors of the Department of Restorative Dentistry, School of Dentistry of Ribeirão Preto USP, São Paulo, Brazil
}

\begin{abstract}
Proposition: To evaluate the physical properties of flow and solubility of pure and improved mineral trioxide aggregate (MTA) cement with the addition of two plasticizing agents: sodium ether polycarboxylate and sodium naphthalene sulfonate at three different concentrations.

Material and Methods: Flow and solubility tests were carried out using the established methodology recommended by the 57 ANSI/ADA and ISO 6876:2012 standards. Pure MTA was used as control group and was compared to the MTA containing sodium ether polycarboxylate and sodium naphthalene sulfonate at concentrations of $0.5 \%, 1.0 \%$ and $1.5 \%$. Data were analyzed by one-way analysis of variance followed by a post-hoc Tukey test at a $5 \%$ significance level.
\end{abstract}

Results: Sodium ether polycarboxylate increased the MTA flow at the three concentrations. The flow increased with increasing concentration $(\mathrm{P}<0.05)$. Sodium sulfonate naphthalene also facilitated flow, though it was inferior to sodium ether polycarboxylate. Sodium naphthalene sulfonate promoted a significant increase in the solubility of MTA $(p=0.000)$.

Conclusions: The additives improved the physical properties of MTA. Sodium ether polycarboxylate was found to be superior to sodium naphthalene sulfonate at all concentrations.

Keywords: Endodontic cement, MTA, Additives, Physical properties

\section{Introduction}

Several materials are commercially available for the treatment of endodontic lesions. However, with advancing scientific progress, the need to develop new materials with more accurate responses and concrete results arose. On this concern, Mineral trioxide aggregate (MTA)is a promising material with clinically innovative characteristics. ${ }^{1}$
The formulation of MTA is like commercial Portland cement, except for the addition of bismuth oxide, offering radio capacity to the material. ${ }^{2}$ MTA exhibits low contraction and long setting time, ${ }^{3}$ low degree of solubility, biocompatibility, osteo inductive capacity, adequate $\mathrm{pH}$, non resorbable properties, and induces the calcareous carbonation of damaged zones. ${ }^{4-6}$ The mechanism of action of MTA is like calcium hydroxide and involves the release of calcium and hydroxyl ions, which induces the formation of a hard tissue bridge,

\begin{tabular}{|l|l|}
\hline \hline Quick Response Code: & *Corresponding author: Ricardo Novak Savioli, School of Dentistry of Ribeirão Preto-Via do \\
Café s/n. Ribeirão, São Paulo, Brazil \\
Received: 06 July, $2021 \quad$ Published: 20 August, 2021 \\
Citation: Santos LG, Gabriel AES, Filho AMC, Savioli RN. Comparison of Flow and Solubility \\
Properties of Mineral Trioxide Aggregate Cement with Two Additive Plasticizing Agents: An In \\
Vitro Study. SOJ Den Oral Disor. 2021;1(3):1-5. DOI: 10.53902/SOJD0D.2021.01.000513
\end{tabular}


promoting site repair. MTA powder is composed of fine hydrophilic particles that render it ideal moisture. This property is essential for its application in Para endodontic surgeries..$^{5-7}$

MTA expands after hardening. The expansion, combined with low solubility, is responsible for its sealing capacity. ${ }^{8}$ MTA can be used forapexification, retro filling, and root and furcal perforation, as it seals the communication pathways between the root canal system and the surrounding tissues. ${ }^{9,10}$ MTA is considered the most appropriate material for the treatment of root perforations. ${ }^{11-13}$

MTA properties that hinder its clinical applications are low flow and long setting time. ${ }^{14}$ Previous studies have proposed the incorporation of additives into MTA to improve its unsatisfactory physical properties. ${ }^{15-17}$ Several supplements, such as calcium chloride, sodium hydrogen phosphate, and a water-based lubricant, have been added to decrease the long setting time of MTA. ${ }^{15,16}$ The addition of $1 \%$ methylcellulose and $2 \%$ calcium chloride to MTA increased its compressive strength and shortened the setting time. ${ }^{18}$ The calcium lactate gluconate has also been reported as an accelerator to decrease setting time and improve the handling properties of MTA. ${ }^{18}$ Moreover, polycarboxylate sodium ether and sodium naphthalene sulfonate are excellent plasticizing agents for mineral oxide cements. $^{19}$

An accurate analysis of the chemical safety data sheet (SDS) classifies the plasticizer additives (polycarboxylate and naphthalene) at level three toxicity. This degree of toxicity is equal to that promoted byeugenol, which is widely used in dentistry; therefore, the additives can be suitable for dental use. In this study, we tested the flow and solubility of MTA with sodium naphthalene sulfonate and sodium ether polycarboxylate additives, following the ADA (American Dental Association) and ISO 6876 (2012) recommendations.

\section{Proposition}

This aims to elucidate the physical properties (flow and solubility) of pure MTA cement combined with plasticizing agents, sodium naphthalene sulfonate or sodium ether polycarboxylate at concentrations of $0.5 \%, 1.0 \%$ and $1.5 \%$.

\section{Materials and Methods}

The flow and solubility tests were carried out according to standard 57 ANSI/ADA ${ }^{20}$ and ISO 6876. ${ }^{21}$ Seven groups were created for the study, pure MTA cement (control group) and MTA with the addition of two plasticizers, sodium naphthalene sulfonate (Cemix 2000-Vedacit, Brazil) and sodium ether polycarboxylate (Adi-Super H35-Aditibras, Brazil) at concentrations of 0.5\%, 1.0\% and $1.5 \%$.

\section{Preparation of plasticizing solutions}

The volume of material needed for the corresponding amount of MTA powder was calculated and diluted in $100 \mathrm{~mL}$ of distilled and deionized water. Because sodium naphthalene sulfonate is a liquid, the dilution was carried out directly in distilled and deionized wa- ter. To obtain sodium ether polycarboxylate solution, the powder was diluted in water with a magnetic stirrer until completely dispersion.

\section{Powder/liquid ratio, handling and working times}

The powder/liquid ratio was fixed as directed by the manufacturer at $2.5 \mathrm{~g}$ of powder for $1.0 \mathrm{~mL}$ of liquid. The handling time was set at 90 seconds and the maximum working time was set at $10 \mathrm{~min}$. The powder was weighed on a $0.01 \mathrm{~g}$ precision scale (Bel Engineering SRL model ALBIL001, Italy) and the liquid pipetted with an automatic pipette (Transferpette $® S$ ) set to $1.0 \mathrm{~mL}$.

\section{Flow analysis}

A cement volume of $0.5 \mathrm{~mL}$ was withdrawn and placed on a glass plate. After $180 \pm 5 \mathrm{~s}$ from the onset of mixing, a system consisting of a glass plate of $60 \times 60 \mathrm{~mm}$ and additional weight was placed centrally on top of the softened material, resulting in a total load of $120 \mathrm{~g}$. Ten minutes after the onset of the mixing, the weight was removed and, with the help of a TESA-branded digital caliper, the larger and smaller diameters of the disc formed by the compressed cement were noted. This measurement was carried out in cases where the diameters differed by no greater than $1 \mathrm{~mm}$. The flow of the material was taken to be the arithmetic mean of the two measurements. This procedure was repeated thrice for each group. The flow was determined by the arithmetic mean of these three measurements and approximated to the nearest millimeter.

\section{Solubility analysis}

Specimens measuring $1.5 \mathrm{~mm}$ in thickness and $20 \mathrm{~mm}$ in diameter were obtained with the aid of Teflon molds. A waterproof nylon thread was inserted in the cement mass to support the specimen during the test. The specimens were weighed on a Uni Bloc precision scale of German origin to the nearest $0.001 \mathrm{~g}$. Subsequently, the sample was suspended by the nylon thread and placed inside a container containing $50 \mathrm{~mL}$ of distilled and deionized water. Care was taken that there was no contact between the sample and the inner surface of the container. The set was closed and placed in an incubator at $37^{\circ} \mathrm{C}$ for 7 days.

After 7 days, the sample was removed, rinsed with distilled and deionized water, and the excess material was removed with the help of an absorbent tissue. The sample was suspended by the nylon thread in a dehumidifier containing concentrated sulfuric acid for $48 \mathrm{~h}$. After this period, the sample was removed and a second weighing was carried out, again to the nearest $0.001 \mathrm{~g}$. The mass loss of each sample was noted, expressed as the percentage of the original mass of the material. This loss pertains to the solubility of the tested material. The solubility of the tested material was calculated as the mean of two the determinations, approximately to the nearest $0.1 \%$.

\section{Data analysis}

The data exhibited a normal distribution (Shapiro-Wilk test) and were analysed by one-way ANOVA and Tukey post-test, with a significance of 5\%, using the SPSS software (IBM, USA), version 25. 


\section{Results}

\section{Flow test}

Table 1 contains the Analysis of Variance for the flow test of the different cements. Table 2 shows the results obtained for the flow tests of the analyzed materials. The recommendation of Standard ADA $57^{20}$ reports that the disc formed by the cement should be at least $25 \mathrm{~mm}$ in diameter. Thus, only the diameter of the pure MTA was lesser than the accepted criteria. The ANOVA indicated a significant difference among the samples $(\mathrm{p}=0.000)$. Pure MTA had the lowest flow rate. The results obtained with sodium naphthalene sulfonate, regardless of the concentration, were statistically similar and differed from the others. This group displayed flow that was higher than pure MTA but lower than sodium ether polycarboxylate. The addition of sodium ether polycarboxylate increased MTA flow, exceeding the values obtained by adding sodium naphthalene sulfonate. The flow rates were statistically different from each other for all concentrations. The higher the concentration of sodium ether polycarboxylate, the higher was the flow.

\section{Solubility test}

Table 3 shows the Analysis of Variance for the solubility test of the different cements. Table 4 displays the results of the solubility test. The ADA 57 standard ${ }^{20}$ recommends that the material should not exceed $3 \%$ of its mass loss. The analysis of the solubility test demonstrates that all the tested materials had higher solubility than the maximum allowed by the standard. The ANOVA indicated a significant difference among the samples $(p=0.000)$. Tukey test demonstrated that the addition of naphthalene increased the solubility of the MTA cements. The polycarboxylate led to a slight increase in solubility of MTA cements, statistically like pure MTA cement.

Table 1: One way analysis of variance for the flow test of the different cements.

\begin{tabular}{|l|l|l|l|l|l|}
\hline Source of Variance & DF & Sum of Squares & Mean Squares & F value & p-value \\
\hline Groups & 6 & 2839.27 & 473.212 & 269.2 & $0.000 *$ \\
\hline Residual & 14 & 24.61 & 1.758 & & \\
\hline Total & $\mathbf{2 0}$ & $\mathbf{2 8 6 3 . 8 8}$ & & & \\
\hline
\end{tabular}

Table 2: Flow test of the analyzed cements (in $\mathrm{mm}$ ).

\begin{tabular}{|l|l|l|l|l|}
\hline Cement & Diameter $(\mathbf{m m})$ & SD & $\mathbf{9 5 \%} \mathbf{C I}$ & Tukey test* \\
\hline $1.5 \%$ polycarboxylate & 53.32 & 1.579 & $(51.678 ; 54.962)$ & $\mathrm{a}$ \\
\hline $1.0 \%$ polycarboxylate & 44.132 & 2.152 & $(42.49 ; 45.78)$ & $\mathrm{b}$ \\
\hline $0.5 \%$ polycarboxylate & 33.187 & 1.18 & $(31.545 ; 34.828)$ & $\mathrm{c}$ \\
\hline $1.5 \%$ naphthalene & 28.417 & 1.445 & $(26.775 ; 30.058)$ & $\mathrm{d}$ \\
\hline $1.0 \%$ naphthalene & 26.537 & 1.162 & $(24.895 ; 28.178)$ & $\mathrm{d}$ \\
\hline $0.5 \%$ naphthalene & 25.323 & 0.441 & $(23.682 ; 26.965)$ & $\mathrm{d}$ \\
\hline Pure MTA & 15.963 & 0.388 & $(14.322 ; 17.605)$ & $\mathrm{e}$ \\
\hline
\end{tabular}

*Equal letters represent statistical similarity among groups $(\mathrm{p}<0.05)$.

Table 3: One way analysis of variance for the solubility test of the different cements.

\begin{tabular}{|l|l|l|l|l|l|}
\hline Source of Variance & DF & Sum of Squares & Mean Squares & F value & p-value \\
\hline Groups & 6 & 244.423 & 7.4039 & 35.1 & $0.000 *$ \\
\hline Residual & 14 & 2.953 & 0.211 & & \\
\hline Total & $\mathbf{2 0}$ & $\mathbf{4 7 . 3 7 7}$ & & & \\
\hline
\end{tabular}

Table 4: Solubility test of the analyzed cements (\% weight loss).

\begin{tabular}{|l|l|l|l|l|}
\hline Cement & Weight loss $\mathbf{( \% )}$ & SD & $\mathbf{9 5 \%}$ CI & Tukey test* \\
\hline $1.0 \%$ naphthalene & 10.83 & 0.649 & $(10.261 ; 11.399)$ & $\mathrm{a}$ \\
\hline $1.5 \%$ naphthalene & 9.683 & 0.449 & $(9.115 ; 10.252)$ & $\mathrm{ab}$ \\
\hline $0.5 \%$ naphthalene & 8.582 & 0.301 & $(8.092 ; 9.072)$ & $\mathrm{bc}$ \\
\hline $0.5 \%$ polycarboxylate & 7.444 & 0.238 & $(6.954 ; 7.935)$ & $\mathrm{cd}$ \\
\hline $1.0 \%$ polycarboxylate & 7.097 & 0.532 & $(6.528 ; 7.665)$ & $\mathrm{d}$ \\
\hline Pure MTA & 6.937 & 0.557 & $(6.368 ; 7.505)$ & $\mathrm{d}$ \\
\hline $1.5 \%$ polycarboxylate & 6.673 & 0.412 & $(6.105 ; 7.242)$ & $\mathrm{d}$ \\
\hline
\end{tabular}

*Equal letters represent statistical similarity among groups $(\mathrm{p}<0.05)$. 


\section{Discussion}

Tricalcium silicate cements have excellent biological properties based mainly on alkaline $\mathrm{pH}$, which induces mineralization. ${ }^{22}$ After placement, the material releases hydroxyl ions, which increase the $\mathrm{pH}$ of the environment and promote an inflammatory reaction that results in the formation of hydroxyapatite, ${ }^{23}$ along with dentin. ${ }^{24}$ This material results in a hostile environment for microbial survival and proliferation. ${ }^{25}$

Despite its significant biological advantage, its use is hindered by its low plasticity, making its insertion into small spaces and root canals complex. ${ }^{11}$ To solve this problem; MTA repair HP (high plasticity) was commercially available in 2018. According to the manufacturer (Angelus, Londrina, PR, Brazil), its formulation is like the conventional MTA, with the addition of a plasticizer.

In our study, sodium polycarboxylate ether and sodium naphthalene sulfonate were preferred as additives in MTA because they are well-known ${ }^{26,27}$ and highly efficient plasticizers. ${ }^{28,29}$ The $0.5 \%$, $1.0 \%$ and $1.5 \%$ concentrations are following published reports. ${ }^{11}$ The introduction of $0.05 \%$ to $1.50 \%$ of additives in the material decreased viscosity and increased setting time.

The results indicate that a plasticizing agent significantly increased the flow, emphasizing sodium polycarboxylate ether that exhibited higher values than pure MTA and the sodium naphthalene sulfonate additive.

Sodium ether polycarboxylate promoted increased MTA flow at the three concentrations tested. The higher the concentration of the agent, the greater the increase. The results obtained using sodium naphthalene sulfonate indicates that this agent increases the plasticity of MTA but not as much as those observed with sodium ether polycarboxylate. The increase in the concentration of sodium naphthalene sulfonate did not increase plasticity. Solubility is the loss of mass of a material during a period of immersion in water. ${ }^{6}$ It is a characteristic of calcium silicate-based cements. Their biological properties are attributed to the release of hydroxyl ions, which is only possible if solubilization of the material occurs, at least in its initial phase..$^{30}$

Overall, the translation of the laboratory solubility tests to clinical practice requires some considerations. A high solubility value in distilled water from the previously used materials is associated with the high release of calcium and hydroxyl ions, which leaves gaps. On the other hand, when immersed in bodily fluids, the calcium and hydroxyl ions in the materials combine with the phosphate in the surrounding fluids, causing a surface layer of calcium phosphate to fill the open gaps. ${ }^{31}$ The solubility and porosity of tricalcium silicate materials (MTA type) in distilled water do not predict such materials' actual stability and integrity under in vivo conditions. ${ }^{31}$ The MTA Fill apex has higher solubility and gap quantity in the dentin/ sealer interface than the AH Plus sealer. ${ }^{32}$ Regarding solubility, it is evident that naphthalene at concentrations above $1.0 \%$ significantly increased the solubility of the cement and that polycarboxylate did not exhibit such an effect at any of the concentrations studied.
Further studies still need to be carried out to adapt the MTA to the expectations of professionals and requirements of technical standards that regulate the physiochemical behavior of root canal filling materials.

\section{Conclusion}

Considering the limitation of an in vitro test, we can conclude that the addition of plasticizing agents improves the flow of MTA. The sodium ether polycarboxylate is considerably superior to sodium naphthalene sulfonate at the concentrations tested. The addition of sodium ether polycarboxylate and sodium naphthalene sulfonate did not increase the solubility of MTA cement.

\section{Acknowledgments}

None.

\section{Funding}

None.

\section{Conflicts of Interest}

Author declares that there is no conflict of interest.

\section{References}

1. Schwartz RS, Mauger M, David J, et al. A mineral trioxide aggregate: a new material for endodontics. J American Dental Assoc. 1999;130(7):967-975.

2. Girdea M, Ciobano G, Amariei C, et al. Advantages of Pro Root MTA in treating periapical lesions. Clinical cases. Oral Health Dental Management. 2006;5(4):34-40.

3. Chen S, Shi L, Luo J, et al. Novel Fast-Setting Mineral Trioxide Aggregate: Its Formulation, Chemical-Physical Properties, and Cytocompatibility. ACS Applied Materials \& Interfaces. 2018;10(24):20334-20341.

4. Costa JÁ, Rached júnior FA, Souza Gabriel AE, et al. Push-out strength of methacrylate resin-based sealers to root canal walls. Int Endod J. 2010;43(8):638-706.

5. Prati C, Gandolfi MG. Calcium silicate bioactive cements: biological perspectives and clinical applications. Dent Mater. 2015;31(4):351370.

6. Jafari F, Jafari S. Composition and physicochemical properties of calcium silicate-based sealers. J Clin Exp Dent. 2017;9(10):1249-1255.

7. Carvalho MGP, Perez WB, Matter SB, et al. Apicectomy followed by retrograde filling with mineral trioxide aggregate (MTA)-case report. Rev Endod Pesq Ens. 2005;1(2):1-8.

8. Lopes HP, Siqueira JF. Endodontics. Biology and Technique. Ed. Saraiva. 4 ed. 2015.

9. Tawil PZ, Duggan DJ, Galicia JC. Mineral trioxide aggregate (MTA): its history, composition, and clinical applications. Compend Contin Educ Dent. 2015;36(4):247-252.

10. Pittford TR, Torabinejad M. Using mineral trioxide aggregate as a pulp-capping material. J Am Dent Assoc. 1996;127(10):1491-1494.

11. Silva Neto JD, Schnaider TB, Gragnani A, et al. Portland cement with additives in the repair of furcation perforations in dogs. Acta Cir Bras. 2012;27(11):809-814.

12. Aggarwal V, Singla M, Miglani S, et al. Comparative evaluation of pushout bond strength of Pro Root MTA, Biodentine, and MTA Plus in furcation perforation repair. J Conservative Dentistry. 2013;16(5):462-465. 
13. Solanki NP, Venkappa KK, Shah NC. Biocompatibility and sealing ability of mineral trioxide aggregate and bio dentine as root-end filling material: A systematic review. J Conserv Dent. 2018;21(1):10-15.

14. Dawood AE, Parashos P, Wong RHK, et al. Calcium silicate-based cements: composition, properties, and clinical applications. J Investigative and Clinical Dentistry. 2015;8(2):e12195.

15. Wiltbank KB, Schwartz SA, Schindler WG. Effect of selected accelerants on the physical properties of mineral trioxide aggregate and Portland cement. J Endod. 2007;33(10):1235-1238.

16. Kulan P, Karabiyik O, Kose GT, et al. Biocompatibility of accelerated mineral trioxide aggregate on stem cells derived from human dental pulp. J Endod. 2016;42(2):276-279.

17. Ber BS, Hatton JF, Stewart GP. Chemical modification of Pro Root MTA to improve handling characteristics and decrease setting time. J Endod.2007;33(10):1231-1234.

18. Hsieh SC, Teng NC, Lin YC. A novel accelerator for improving the handling properties of dental filling materials. J Endod. 2009;35(9):12921295.

19. Lyra JS. Studyof the influence of commercial polycarboxy late on the hydration, rheology and physico-chemistry of cement surface. São Paulo: Master's Thesis [Universidade de São Paulo-Escola Politecnica], 2010.

20. ANSI/ADA 57 Specification. Endodontics filling materials.

21. ISO 6876:2012. Dentistry-Root canal sealing materials.

22. Duarte MAH, Demarchi ACCO, Yamashita JC, et al. pH and calcium ion release of 2 root-end filling materials. Oral Surgery Oral Medicine Oral Pathology. 2003;95(3):345-347.
23. Meyer JL, Eanes ED. A Thermodynamic Analysis of the Amorphous to Crystalline Calcium Phosphate Transformation. Calcif Tiss Res. 1978;25(1):59-68.

24. Danesh G, Dammaschke T, Gert HUV, et al. A comparative study of selected propreties of Pro Root mineral trioxide aggregate and two Portland cements. Int Endod J. 2006;39(3):213-219.

25. Gandolfi MG, Siboni F, PratiC. Chemical-physical properties of Thera Cal, a novel light-curable MTA-like material for pulp capping. Int Endod J. 2012;45(6):571-579.

26. Oliveira IR, Studart AR, Pileggi RG, et al. Dispersion and Packaging of Particles: Basic Principles and Applications in Ceramic Processing. São Paulo: Fazendo Arte Editorial. p. 224, 2000.

27. Gouvêa D, Murad BBS. Influence of acid-basic characteristic of $\mathrm{Al}_{2} \mathrm{O}_{3}$ or $\mathrm{SnO}_{2}$ surfaces on the stability of ceramic suspensions with commercial dispersants. Cerâmica. 2001;47(301):51-56.

28. Rixom MR, Mailvaganam NP. Chemical admixtures for concrete, ed. T. Edition, New York, p 437, 1999.

29. Mehta PK, Monteiro PJM. CONCRETE Microstructure, Properties and Materials.3o ed. p. 674, 2008.

30. Gandolfi MG, Siboni F, Primus CM, et al. Ion Release, Porosity, Solubility, and Bioactivity of MTA Plus Tricalcium Silicate. J Endod. 2014;40(10):1632-1637.

31. Siboni F, Taddei P, Prati C, et al. Properties of Neo MTA Plus and MTA Plus cements for endodontics. Int Endod J. 2017;50(s2):83-94.

32. Amoroso-Silva PA, Guimaraes BM, Marciano MA, et al. Microscopic analysis of the quality of obturation and physical properties of MTA Fillapex. Microsc Res Tech. 2014;77(12):1031-1036. 